\title{
Hwanggeumchal sorghum extract enhances BMP7 and GH signaling through the activation of Jak2/STAT5B in MC3T3-E1 osteoblastic cells
}

\author{
YOUN HEE JOUNG ${ }^{1 *}$, EUN JOUNG LIM ${ }^{1 *}$, PRAMOD DARVIN $^{1}$, \\ JU WOONG JANG ${ }^{2}$, KYUNG DO PARK ${ }^{3}$, HAK KYO LEE ${ }^{3}$, HEUI SOO KIM ${ }^{4}$, \\ BYUNG WOOK CHO ${ }^{5}$, TAEKYU PARK ${ }^{6}$, SUMI CHUNG ${ }^{7}$, JONG HWAN PARK $^{8}$ and YOUNG MOK YANG ${ }^{1}$ \\ ${ }^{1}$ Department of Pathology, School of Medicine, Institute of Biomedical Science and Technology, Konkuk University, \\ Seoul 143-701; ${ }^{2}$ Korea Bone Bank Co, Ltd., Seoul 153-782; ${ }^{3}$ Genomic Informatics Center, Hankyong National University, \\ Anseong 456-749; ${ }^{4}$ Department of Biological Sciences, College of Natural Sciences, Pusan National University; \\ ${ }^{5}$ Department of Animal Science, College of Life Science, Pusan National University, Busan 609-735; \\ ${ }^{6}$ Department of Biotechnology, College of Biomedical and Health Science, Konkuk University Glocal Campus, \\ Chung-Ju 380-701, Republic of Korea; ${ }^{7}$ Department of Business, University of Texas at Austin, Austin, TX 78712, USA; \\ ${ }^{8}$ College of Pharmacy, Dongguk University, Seoul 100-715, Republic of Korea
}

Received February 12, 2013; Accepted July 11, 2013

DOI: $10.3892 / \mathrm{mmr} .2013 .1593$

\begin{abstract}
Sorghum is a principal cereal food in a number of parts of the world and is critical in folk medicine in Asia and Africa. However, its effects on bone are unknown. Growth hormone $(\mathrm{GH})$ is a regulator of bone growth and bone metabolism. GH activates several signaling pathways, including the Janus kinase (Jak)/signal transducer and activator of transcription (STAT) pathways, thereby regulating expression of genes, including insulin-like growth factor (IGF)-1. Bone morphogenetic proteins (BMPs) induce the differentiation of cells of the osteoblastic lineage, increasing the pool of IGF-1 target cells, the mature osteoblasts. In the present study, the effects of Hwanggeumchal sorghum extracts (HSE) on GH signaling via the Jak/STAT pathway in osteoblasts were investigated. HSE was not observed to be toxic to osteoblastic cells and increased the expression of BMP7 and GH-related proteins, including STAT5B, p-STAT5B, IGF-1 receptor (IGF-1R), growth receptor hormone (GHR) and Jak2 in MC3T3-E1 cells. In addition, HSE increased BMP7 and GHR mRNA expression in MC3T3-E1
\end{abstract}

Correspondence to: Dr Young Mok Yang, Department of Pathology, School of Medicine, Institute of Biomedical Science and Technology, Konkuk University, 1 Hwayang-dong, Gwangjin-gu, Seoul 143-701, Republic of Korea

E-mail: ymyang@kku.ac.kr

${ }^{*}$ Contributed equally

Key words: Hwanggeumchal sorghum extracts, bone morphogenetic protein 7, Janus kinase 2, signal transducers and activators of transcription $5 \mathrm{~B}$, growth hormone, insulin-like growth factor-1 receptor, growth hormone receptor, osteoblasts cells. The expression of HSE-induced BMP7 and GHR was inhibited by AG490, a Jak2 kinase inhibitor. The observations indicate that HSE-induced signaling is similar to GH signaling via the GHR-Jak2 signaling axis. Using small interference RNA (siRNA) analysis, STAT5B was found to play an essential role in HSE-induced BMP7 and GH signaling in MC3T3-E1 cells. Results of the current study indicate that HSE promotes bone growth through activation of STAT5B.

\section{Introduction}

Growth hormone (GH) and insulin-like growth factor (IGF)-1 are important regulators of bone homeostasis and are central to normal longitudinal bone growth and bone mass (1). GH signaling via its receptor is mediated by cascades of protein phosphorylation resulting in activation of nuclear proteins and transcription factors. The growth hormone receptor (GHR) itself is not a tyrosine kinase (2). Instead, when GH binds to the GHR, it induces receptor homodimerization and activation of the GHR-associated tyrosine kinase, Janus kinase 2 (Jak2) $(3,4)$. Jak2 is then phosphorylated and in turn, phosphorylates the GHR and signal transducers and activators of transcription (STAT) proteins. Upon phosphorylation, STAT proteins, homodimerize or heterodimerize, translocate to the nucleus, bind to their appropriate DNA response element and stimulate transcription of GH-regulated genes, including IGF-1 (5). GH exerts its effects directly and via IGF-1, which signals by activating the IGF-1 receptor (1R). The IGF-1R is a cell-surface receptor that contains intrinsic tyrosine kinase activity within its intracellular domain (6).

Bone is a living organ that undergoes remodeling throughout life (7). Bone remodeling involves the removal of mineralized bone by osteoclasts followed by the formation of the bone matrix through the osteoblasts that subsequently 
become mineralized (8). The major regulators of bone remodeling include $\mathrm{GH}$, parathyroid hormone (PTH), IGF-1, transforming growth factor- $\beta$ (TGF- $\beta$ ) and bone morphogenetic protein (BMP) (7).

BMPs constitute the largest subgroup of the TGF- $\beta$ superfamily of cytokines $(9,10)$. BMP molecules appear to induce bone formation in a stepwise manner, with individual BMP molecules functioning at various stages of osteoblastic differentiation and osteogenesis $(11,12)$. Specifically, BMP7 is known to be an osteogenesis-stimulating factor and has been widely reported to induce osteogenic differentiation of human mesenchymal stem cells (hMSCs) $(13,14)$. Since BMP7 controls the development and maintenance of multiple physiological processes in the human body, it is not surprising that aberrant expression of BMP7 has been found to be associated with a variety of diseases $(15,16)$.

Sorghum is rich in phytochemical components, including tannins, phenolic acids, anthocyanins, flavanoids and policosanols, with a potential to benefit human health (17). Recent studies have demonstrated that sorghum has an anti-esophageal cancer and cholesterol-lowering effect, decreasing the risk of cardiovascular disease and in particular, revealing a high antioxidant activity $(18,19)$. However, the effects of Hwanggeumchal sorghum extracts (HSE) have not yet been reported in bone cells. Natural substances have been investigated as candidate materials to be used in bone-related diseases. These natural extracts have been used to develop new drugs through a combination of effective single compounds or in combination with existing commercial drugs, including estrogen or GH products used to prevent bone loss $(20,21)$.

Notably, the role of Jak/STAT signaling in osteoblasts appears to be relatively obscure. Recently, we reported STAT5B as a mediator of MSC proliferation in response to methylsulfonylmethane (MSM) stimulation (22). In the present study, the role of HSE-enhanced BMP7 and GH-signaling in Jak2/STAT5B signaling was investigated in MC3T3-E1 cells.

\section{Materials and methods}

Antibodies and reagents. Dulbecco's modified eagle's medium (DMEM), MEM, fetal bovine serum and trypsin-EDTA were purchased from Gibco-BRL (Carlsbad, CA, USA). IGF-1R, phospho-IGF-1R, STAT5B, Jak2 and GHR primary antibodies, and the secondary antibodies (HRP-conjugated goat anti-mouse IgG and HRP-conjugated donkey anti-rabbit IgG) were purchased from Santa Cruz Biotechnology, Inc. (Santa Cruz, CA, USA). BMP7 antibody was purchased from Abcam (Cambridge, UK). An antibody against phospho-STAT5B was obtained from Upstate Biotechnology (Lake Placid, NY, USA). The anti-actin antibody and 3-(4,5-dimethylthiazol-2-yl)-2,5-diphenyltetrazolium bromide (MTT) were obtained from Sigma-Aldrich (St. Louis, MO, USA). The RNeasy mini kit was purchased from Qiagen (Hilden, Germany). The reverse transcription-polymerase chain reaction (RT-PCR) Premix kit and BMP7, GHR and 18S primers for RT-PCR were purchased from Bioneer Corporation (Daejeon, Korea). The ON-TARGETplus SMARTpool small interference RNA (siRNA) targeting STAT5B and ON-TARGETplus non-targeting siRNA were purchased from Dharmacon (Pittsburgh, PA, USA). The enhanced chemiluminescence
(ECL) plus detection kit was purchased from Amersham Pharmacia Biotech (Piscataway, NJ, USA). The coomassie protein assay kit and Restore western blot stripping buffer were purchased from Pierce Biotechnology, Inc. (Rockford, IL, USA).

Extraction and characterization of sorghum. For this study, HS was selected and extracted according to a previously described method (23) with small modifications. The sample $(50 \mathrm{~g})$ was stored at $-36^{\circ} \mathrm{C}$ and ground well prior to use. Ground powder was then extracted with $30 \% 0.1 \mathrm{~N} \mathrm{HCl}$ in acetonitrile. The solution was filtered using Whatman filter paper (Cole-Parmer, Vernon Hills, IL, USA), concentrated and again extracted with $100 \%$ methanol and dried overnight in a freeze dryer. The sorghum extract was characterized for its phenolic content using high performance liquid chromatography (data not shown).

MTT assay. Cell viability was assayed by measuring blue formazan that was metabolized from MTT by mitochondrial dehydrogenase, which is active only in live cells. One day prior to drug application, MC3T3-E1 cells were seeded in 96-well flat-bottomed microtiter plates (3,000-5,000 cells/well). MC3T3-E1 cells were incubated for $24 \mathrm{~h}$ with various concentrations of HSE. MTT $(20 \mu \mathrm{l} ; 5 \mathrm{mg} / \mathrm{ml})$ was added to each well and incubated for $4 \mathrm{~h}$ at $37^{\circ} \mathrm{C}$. The formazan product was dissolved by adding $200 \mu \mathrm{l}$ DMSO to each well and the plates were read at $550 \mathrm{~nm}$. All measurements were performed in triplicate and each experiment was repeated at least three times.

Western blot analysis. MC3T3-E1 cells were treated with the indicated HSE concentrations $(0,10,20$ and $40 \mu \mathrm{g} / \mathrm{ml})$ for $24 \mathrm{~h}$. MC3T3-E1 cells were untreated or pretreated with $50 \mu \mathrm{M}$ AG490 for $4 \mathrm{~h}$ then treated with $30 \mu \mathrm{g} / \mathrm{ml} \mathrm{HSE}$ for $24 \mathrm{~h}$. Cells were lysed in whole lysis buffer [50 mM Tris- $\mathrm{HCl},(\mathrm{pH} 7.5)$, $5 \mathrm{mM}$ EDTA, $150 \mathrm{mM} \mathrm{NaCl}$ and $1 \%$ Triton X-100] containing protease and phosphatase inhibitors (1 mM PMSF, $2 \mu \mathrm{g} /$ ml leupeptin, $4 \mu \mathrm{g} / \mathrm{ml}$ aprotinin and $1 \mu \mathrm{g} / \mathrm{ml}$ pepstatin) and protein concentrations were determined using the coomassie protein assay kit (Pierce Biotechnology, Rockford, IL, USA). An equivalent amount of protein extracts from each sample was electrophoresed on 10\% SDS-PAGE and transferred onto nitrocellulose membranes. Membranes were blocked for $1 \mathrm{~h}$ with $5 \%$ non-fat milk in T-TBS buffer [20 mM Tris- $\mathrm{HCl}$ (pH 7.6), $137 \mathrm{mM} \mathrm{NaCl}$ and 0.1X Tween-20] and incubated overnight at $4^{\circ} \mathrm{C}$ with primary antibodies (BMP7, STAT5B, p-STAT5B, IGF-1R, GHR, Jak2 and $\beta$-actin). The membranes were washed three times in T-TBS and incubated with the corresponding secondary antibody, anti-mouse or anti-rabbit IgG HRP-conjugate $(1: 1,000)$, in T-TBS with $5 \%$ non-fat milk for $1 \mathrm{~h}$ under agitation at room temperature. Following washing three times in T-TBS, the membranes were developed using the ECL plus kit.

RT-PCR. MC3T3-E1 cells were treated with the indicated concentrations of HSE for $24 \mathrm{~h}$. MC3T3-E1 cells were untreated orpretreated with $50 \mu \mathrm{MAG} 490$ for $4 \mathrm{~h}$ then treated with $30 \mu \mathrm{g} / \mathrm{ml}$ HSE for $24 \mathrm{~h}$. Total RNA was prepared using the RNeasy mini kit and cDNA was synthesized using the AccuPower RT 
PreMix kit (Bioneer Corporation) according to the manufacturer's instructions. PCR was performed using aliquots of cDNA to detect GHR and BMP7. The PCR primer sequences were as follows: BMP7 sense, 5'-GGCTTCTCCTACCCCTACAA-3' and antisense, 5'-GTGGTTGCTGGTGGCTGTGA-3'; GHR sense, 5'-TTCTAAACAGCAAAGGATTAA-3' and antisense, 5'-CACTGTGAAATTCGGGTT TA-3'; 18S primers: sense, 5'-CGGCTACCACATCCAAGGAA-3' and antisense: 5'-CCGGCG TCCCCTCTTAATC-3'. The PCR was conducted under the following conditions: 30 cycles at $94^{\circ} \mathrm{C}$ for $45 \mathrm{sec}$, $60^{\circ} \mathrm{C}$ for $45 \mathrm{sec}$ and $72^{\circ} \mathrm{C}$ for $1 \mathrm{~min}$. Following amplification, the PCR products were analyzed on a $1.2 \%$ agarose gel and visualized by ethidium bromide staining and ultraviolet irradiation.

siRNA assay. MC3T3-E1 cells were grown to 50\% confluence and transfected with ON-TARGETplus SMARTpool siRNA targeting STAT5B or ON-TARGETplus non-targeting siRNA using FuGene 6 (Roche, Basel, Switzerland), according to the manufacturer's instructions. Following transfection (48 h), cells were cultured in serum-free medium for $24 \mathrm{~h}$ and then exposed to $30 \mu \mathrm{g} / \mathrm{ml} \mathrm{HSE}$ for $24 \mathrm{~h}$. STAT5B, p-STAT5B, BMP7 and IGF-1R expression levels were detected using western blot analysis.

Statistical analysis. Data are presented as the mean \pm SEM. Statistical analysis was performed using the student's t-test or one-way analysis of variance (ANOVA) test of the SAS program. These were compared by ANOVA followed by Duncan's multiple range test. $\mathrm{P}<0.05$ was considered to indicate a statistically significant difference.

\section{Results}

HSE cytotoxicity of osteoblast-like cells. To determine the suitability of HSE as an osteoblast growth supporting agent, cytotoxicity of HSE in osteoblast-like cells was examined. MC3T3-E1 cells were treated with increasing concentrations of $\operatorname{HSE}(0,10,20$ and $40 \mu \mathrm{g} / \mathrm{ml})$ for $24 \mathrm{~h}$ and the impact of HSE in MC3T3-E1 cell proliferation was assayed using the MTT assay. No notable cytotoxicity was observed when the cells were exposed to up to $40 \mu \mathrm{g} / \mathrm{ml}$ for $24 \mathrm{~h}$ (Fig. 1). Thus, HSE was used at a concentration of $30 \mu \mathrm{g} / \mathrm{ml}$ for subsequent experiments.

HSE increases GH signaling-related protein expression in osteoblast-like cells. The expression levels of various proteins involved in $\mathrm{GH}$ signaling were assessed by western blot analysis. $\mathrm{GH}$ initiates signals by binding to the GHR to activate tyrosine kinase, Jak2 and downstream pathways, including STAT5B, thereby regulating the expression of genes, including IGF-1. GH exerts effects directly and via IGF-1, which signals by activating the IGF-1R. We hypothesized that HSE increases the expression of BMP7, STAT5B, p-STAT5B, IGF-1R, GHR and Jak2 in osteobast-like cells. As demonstrated in Fig. 2A, HSE treatment increased expression of BMP7, IGF-1R, STAT5B, Jak2 and p-STAT5B in MC3T3-E1 in a dose-dependent manner. These observations indicate that HSE functions via the Jak2/ STAT5B signaling pathway in MSCs. Next, Jak2 was inhibited using AG490, which led to a blockade of HSE-induced BMP7

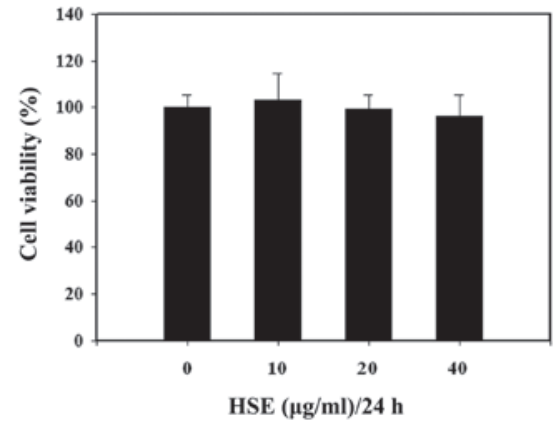

Figure 1. Effects of HSE on viability in MC3T3-E1 cells. MC3T3-E1 cells were cultured in 96-well dishes for $24 \mathrm{~h}$ and then treated with the indicated concentrations of HSE for $24 \mathrm{~h}$. Following incubation, cell viability was evaluated using the MTT assay. Data presented are representative of three independent experiments. HSE, Hwanggeumchal sorghum extracts; MTT, 3-(4,5-dimethylthiazol-2-yl)-2-5-diphenyltetrazolium bromide.

A

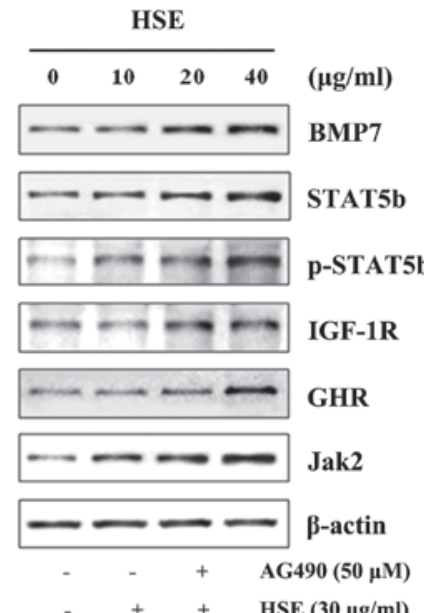

B

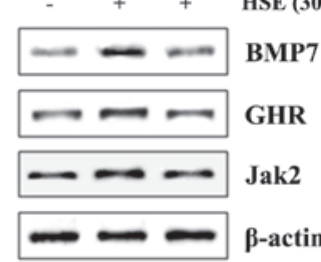

C

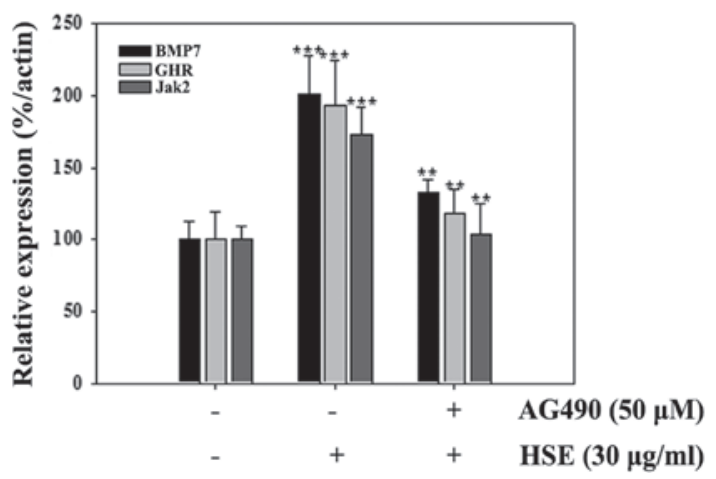

Figure 2. Effects of HSE on the expression of GH signaling-related proteins in MC3T3-E1 cells. (A) MC3T3-E1 cells were treated with increasing concentrations of HSE for $24 \mathrm{~h}$. (B) Cells were left untreated or pretreated with $50 \mu \mathrm{M}$ AG490 for $4 \mathrm{~h}$ then treated with HSE for $24 \mathrm{~h}$. Protein extracts $(20 \mu \mathrm{g})$ were separated by $10 \%$ SDS-PAGE and western blot analysis was performed. $\beta$-actin was used as a protein loading control. (C) The relative levels of BMP7, GHR and Jak2 protein were determined using densitometric analysis and normalized against $\beta$-actin. This image is representative of three independent experiments. $\left({ }^{* *} \mathrm{P}<0.01,{ }^{* * *} \mathrm{P}<0.001\right.$, vs. actin). HSE, Hwanggeumchal sorghum extracts; $\mathrm{GH}$, growth hormone; BMP7, bone morphogenetic protein 7; IGF, insulin-like growth factor; GHR, growth hormone receptor; Jak2, Janus kinase 2. 
and GHR protein expression. HSE-induced BMP7 and GHR protein expression was inhibited by AG490 (Fig. 2B). The relative expression density of protein with respect to actin provided a clear view on the effect of HSE on MC3T3-E1 cells at AG490 (Fig. 2C). These results indicate that HSE-induced signaling is similar to GH signaling via the Jak2/STAT5 pathway.

HSE-induced BMP7 and GHR expression involves Jak2. Next, the role of Jak2 in the enhanced expression of BMP7 and GHR upon HSE treatment was studied using the commercial Jak2 inhibitor, AG490. As demonstrated in Fig. 3A, HSE upregulated BMP7 and GHR mRNA expression in a dose-dependent manner. The relative expression density of mRNA with respect to $18 \mathrm{~S}$ revealed the effect of HSE on MC3T3-E1 cells at various concentration levels (Fig. 3B). The involvement of Jak2 in this augmented expression was analyzed by inhibition of Jak2 using AG490. This inhibition led to a reduction of HSE-induced BMP7 and GHR mRNA expression (Fig. 3C). The relative expression with respect to $18 \mathrm{~S}$ revealed a statistically significant repression in the expression of BMP7 and GHR (Fig. 3D). These results demonstrate that HSE-induced BMP7 and GHR expression increases via Jak2.

HSE-induced BMP7 and GH signaling requires STAT5B activation in MC3T3-E1 cells. To investigate whether STAT5B is involved in the effects of HSE on GH signaling, a siRNA strategy was used. MC3T3-E1 cells were transfected with specific STAT5B siRNA and then exposed to HSE treatment. STAT5B knockdown decreased the basal levels of STAT5B protein expression. Knockdown of STAT5B also inhibited HSE-induced p-STAT5B, BMP7 and IGF-1R expression levels in MC3T3-E1 cells (Fig. 4A). Relative protein expression levels with respect to actin were analyzed to determine the effect of STAT5B in enhanced expression of proteins by HSE (Fig. 4B). These results demonstrated that STAT5B played an essential role in GH signaling activation in MC3T3-E1 cells.

\section{Discussion}

GH is a potent regulator of bone formation (1). In addition, growth factors, including BMPs, play a key role in bone regeneration through growth and differentiation, whether secreted locally or used as stimulators $(11,24)$. Unlike the BMP-induced osteo-inductive Smad pathway, Jak/STAT signaling is frequently associated with proliferation and migration of numerous primary cell lineages (25). In a recent study, we reported that STAT5B is involved in MSM-induced osteoblastic differentiation of MSCs and plays an essential role in MSM-induced GH signaling of C3H10T1/2 cells (22).

The present study was designed to examine the involvement of Jak2/STAT5B signaling in MC3T3-E1 cells following their treatment with HSE. Analysis of cell proliferation using the MTT method was performed with HSE at 10, 20 and $40 \mu \mathrm{g} / \mathrm{ml}$. As demonstrated in Fig. 1, there was no significant difference in the OD values in MC3T3-E1 cells. This observation indicated that there is no notable proliferation inhibition associated with HSE treatment in osteoblast cells. Our next aim was to investigate the effects of HSE on the Jak/STAT pathway by analyzing the expression of BMP7 and GHR in osteoblast-like cells. HSE increased the expression of GH signaling-related proteins, including STAT5B, p-STAT5B, IGF-1R, GHR and Jak2, in MC3T3-E1 cells (Fig. 2A).

Osteoblasts produce a range of growth factors under a variety of stimuli, including IGF, platelet-derived growth factor, TGF- $\beta$ and BMP (26-29). BMP7 is an important inducer of bone formation in vivo and in vitro. The ability of recombinant human BMP7 to induce large volumes of bone makes it an ideal candidate for treating delayed unions and non-unions (30). In the present study, treatment with HSE was found to dependently induce the expression of BMP7 in MC3T3-E1 cells (Figs. 2A and 3A). In addition, inhibition of Jak2 led to suppression of BMP7 expression at the transcriptional and translational levels, indicating the importance of Jak2 in the enhanced expression of BMP7 upon HSE treatment (Figs. 2B and 3B). These results demonstrate that HSE has the ability to maintain bone homeostasis via enhanced expression of BMP7.

Osteoblasts express GHR $(31,32)$ and transmembrane GHR levels are extremely important for GH signaling (33). In general, the expression levels of GHR are regulated and fine tuned through the IGF-1 and IGF binding protein level. Levels of GHR are important in the autocrine loop of GH/IGF-1 and other factors modulating the effect of GH in osteoblasts. In our previous study, HSE was found to dose dependently enhance the expression of GHR in MC3T3-E1 cells. Inhibition of Jak2 and STAT5B revealed a marked decrease in GHR levels, demonstrating the significance of the Jak2/STAT5B signaling axis in the modulation of GHR expression. It is already known that IGF-1R is a necessary factor for maintaining GH-stimulated IGF-1 and IGFBP-3 expression (31). GH induces a GHR-Jak2-IGF-1R complex, indicative of a novel function for IGF-1R (2). In the present study, expression of IGF-1R was also found to increase with HSE treatment (Fig. 2A) and this increase was mediated through STAT5B (Fig. 4). Therefore, we hypothesize that, HSE increases GHR signaling by enhancing the expression of IGF-1R via STAT5B in MC3T3-E1 cells.

GH signals through membrane-associated GHR, which results in the activation of receptor-associated Jaks. Jak2 activation results in the engagement of several intracellular signaling pathways, including STAT-1, -3 and -5 (34-36). The role of Jak2 in osteoblastic cells is well studied. In a recent study, we reported that inhibition of Jak2 results in the inhibition of GH mediated osteoblast differentiation (22), providing an insight to the role of Jak2 in osteoblastic cell lines. In the present study, the elevation of Jak2 levels using HSE revealed a simultaneous elevation in BMP7 and GHR levels. However, the inhibition of Jak2, suppressed the expression of BMP7 as well as GHR levels (Figs. 2B and 3C). The relative expression levels of these proteins revealed a statistically significant decline in the expression of BMP7 and GHR in Jak2 inhibited samples (Figs. 2C and 3D). This confirmed the role of Jak2 in the enhanced expression of BMP7 and GHR in HSE treatment.

STAT5B is an important member of the STAT family for osteoblast proliferation and differentiation (22), owing to GH signaling primarily through the STAT5B/IGF-1R axis (5). 
A

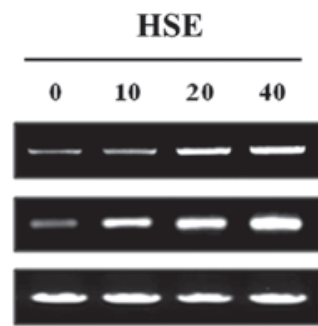

$(\mu \mathrm{g} / \mathrm{ml})$

BMP7

GHR

$18 \mathrm{~S}$

C

$\begin{array}{llll}- & - & + & \text { AG490 }(50 \mu \mathrm{M}) \\ - & + & + & \text { HSE }(30 \mu \mathrm{g} / \mathrm{ml}) \\ - & - & \text { BMP7 } \\ - & - & \text { GHR } \\ - & \end{array}$

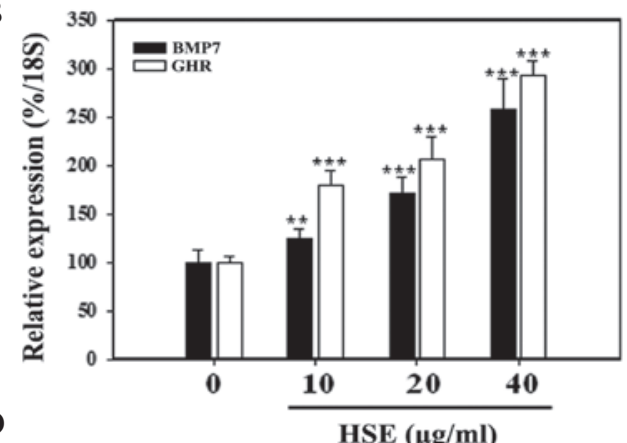

D

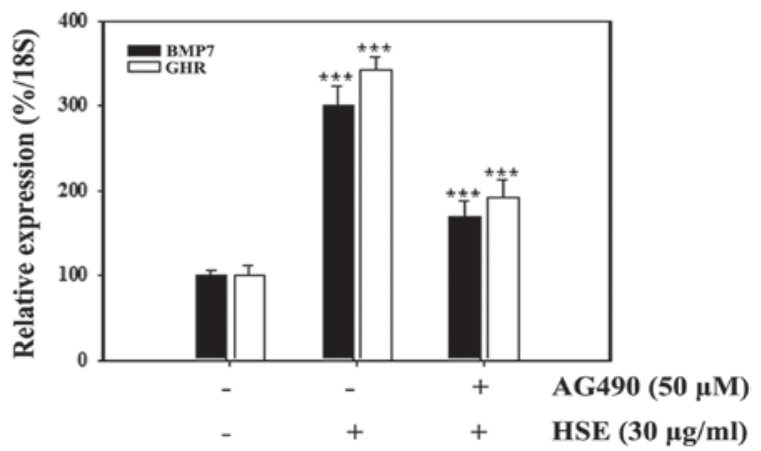

Figure 3. HSE activates the expression of GH signaling-related mRNA in MC3T3-E1 cells. Total RNA was isolated from the MC3T3-E1 cells using an RNeasy kit. The cDNA was amplified using specific primers for BMP7, GHR or 18S. 18S was used as a loading control. (A) MC3T3-E1 cells were treated with the indicated concentrations of HSE for $24 \mathrm{~h}$. (B) The relative levels of BMP7 and GHR mRNA were determined using densitometric analysis and normalized against 18S. (C) MC3T3-E1 cells were left untreated or pretreated with $50 \mu \mathrm{M}$ AG490 for $4 \mathrm{~h}$ then treated with HSE for $24 \mathrm{~h}$. (D) The relative levels of BMP7 and GHR mRNA were determined using densitometric analysis and normalized against $18 \mathrm{~S}$. Data presented are representative of three independent experiments. $\left({ }^{* *} \mathrm{P}<0.01\right.$, ${ }^{* * * *} \mathrm{P}<0.001$, vs 18S). HSE, Hwanggeumchal sorghum extracts; GH, growth hormone; BMP7, bone morphogenetic protein 7; GHR, growth hormone receptor.

A

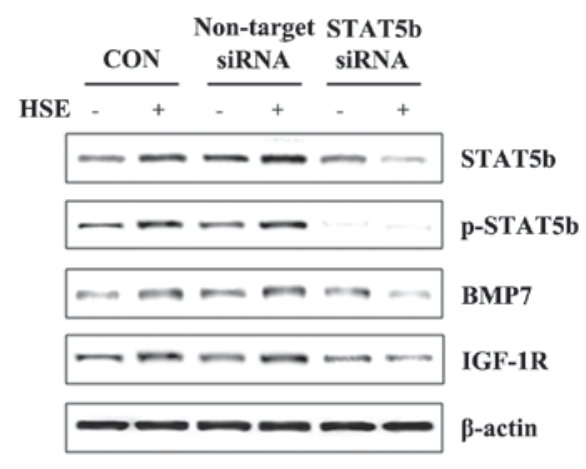

B

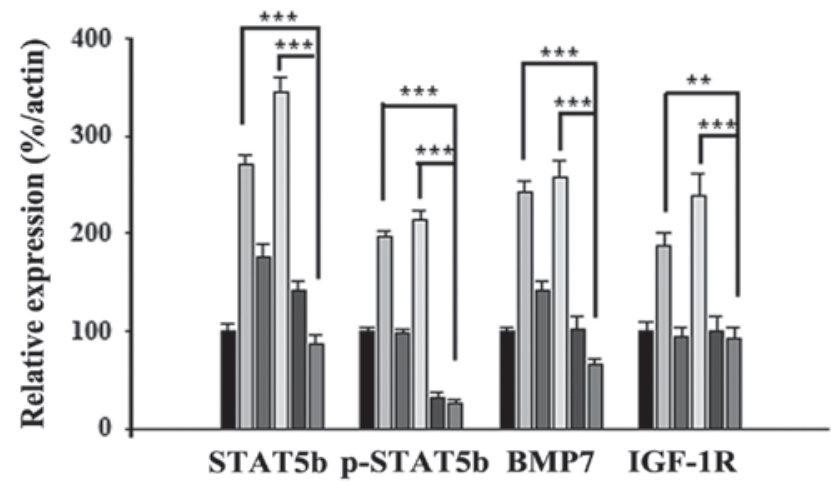

Figure 4. HSE-enhanced BMP7 and GH signaling requires STAT5B activation in MC3T3-E1 cells. (A) MC3T3-E1 cells were transfected with siRNA targeting STAT5B or non-targeting siRNA for $48 \mathrm{~h}$, cells were cultured with serum free medium for $24 \mathrm{~h}$ and then cultured with $30 \mu \mathrm{g} / \mathrm{ml} \mathrm{HSE}$ for $24 \mathrm{~h}$. Protein extracts $(20 \mu \mathrm{g})$ were separated by $10 \%$ SDS-PAGE and western blot analysis was performed. $\beta$-actin was used as a protein loading control. (B) The relative levels of STAT5B, p-STAT5B, BMP7 and IGF-1R protein were determined using densitometric analysis and normalized against $\beta$-actin. Data presented are representative of three independent experiments. $\left({ }^{* *} \mathrm{P}<0.01,{ }^{* * *} \mathrm{P}<0.001\right.$, vs. $\beta$-actin). HSE, Hwanggeumchal sorghum extracts; GH, growth hormone; BMP7, bone morphogenetic protein 7; STAT5B, signal transducers and activators of transcription 5B; IGF, insulin-like growth factor; GHR, growth hormone receptor; IGF-1R, insulin-like growth receptor-1.

This signaling axis has its own importance in osteoblasts, as it modulates the expression of IGF-1, which is the most important autocrine factor in osteoblasts. In addition to the role of STAT5B in the regulation of IGF-1 levels, we found that abolition of STAT5B by specific siRNA, significantly decreases HSE-induced BMP7 and IGF-1R expression in osteoblast-like cells, indicating that the STAT5B signaling pathway functions as a positive modulator of HSE-induced signaling and enhanced expression of BMP7 and GHR (Figs. 2B and 3A).

We hypothesize that HSE signals in osteoblast-like cells through the Jak2/STAT5B axis, similar to GH. In the present study, the ability of HSE to modulate the Jak2/STAT5B 
cascade in osteoblastic cells is reported for the first time. This signaling axis is involved in the somatomedin hypothesis and dual effector theory of $\mathrm{GH} / \mathrm{IGF}-1$ interaction and signaling. HSE signaling enhances the expression of BMP7, GHR and IGF-1R in MC3T3-E1 cells, indicating that the HSE signaling mechanism is important for osteoblast proliferation, differentiation and bone homeostasis.

\section{Acknowledgements}

This study was supported by grants from the Fundamental R\&D Program for Technology of World Premier Materials funded by the Ministry of Trade, Industry \& Energy (no. 2010-0012318) and was partially supported by the Next Generation BioGreen 21 Programs (no. PJ0081062011), Rural Development Administration, Republic of Korea.

\section{References}

1. Giustina A, Mazziotti G and Canalis E: Growth hormone, insulin-like growth factor and the skeleton. Endocr Rev 29: 535-559, 2008 .

2. Stred SE, Stubbart JR, Argetsinger LS, et al: Stimulation by growth hormone $(\mathrm{GH})$ of $\mathrm{GH}$ receptor-associated tyrosine kinase activity. Endocrinology 130: 1626-1636, 1992.

3. Argetsinger LS, Campbell GS, Yang X, et al: Identification of JAK 2 as a growth hormone receptor-associated tyrosine kinase Cell 74: 237-244, 1993.

4. Carter-Su C, Argetsinger LS, Campbell GS, et al: The identification of JAK2 tyrosine kinase as a signaling molecule for growth hormone. Proc Soc Exp Biol Med 206: 210-215, 1994.

5. Herrington J, Smit LS, Schwartz J and Carter-Su C: The role of STAT proteins in growth hormone signaling. Oncogene 19 2585-2597, 2000.

6. Gan Y, Zhang Y, Digirolamo DJ, et al: Deletion of IGF-I receptor (IGF-IR) in primary osteoblasts reduces GH-induced STAT5 signaling. Mol Endocrinol 24: 644-656, 2010.

7. Hadjidakis DJ and Androulakis II: Bone remodeling. Ann NY Acad Sci 1092: 385-396, 2006.

8. Zuo C, Huang Y, Bajis R, Sahih M, Li YP, Dai K and Zhang X: Osteoblastogenesis regulation signals in bone remodeling. Osteoporos Int 23: 1653-1663, 2012.

9. Gazzerro E and Canalis E: Bone morphogenetic proteins and their antagonists. Rev Endocr Metab Disord 7: 51-65, 2006.

10. Kawabata M, Imamura T and Miyaxono K: Signal transduction by bone morphogenetic proteins. Cytokine Growth Factor Rev 9: 49-61, 1998

11. Wozney JM, Rosen V, Byrne M, Celeste AJ, Moutsatsos I and Wang EA: Growth factor influencing bone development. J Cell Sci Suppl 13: 149-156, 1990.

12. Laflamme C, Curt S and Rouabhia M: Epidermal growth factor and bone morphogenetic proteins upregulate osteoblast proliferation and osteoblastic markers and inhibit bone nodule formation. Arch Oral Biol 55: 689-701, 2010.

13. Sampath TK, Maliakal JC, Hauschka PV, et al: Recombinant human osteogenic protein-1 (hOP-1) induces new bone formation in vivo with a specific activity comparable with natural bovine osteogenic protein and stimulates osteoblast proliferation and differentiation in vitro. J Biol Chem 267: 20352-20356, 1992.

14. Vukicevic S, Luyten FP and Reddi AH: Stimulation of the expression of osteogenic and chondrogenic phenotypes in vitro by osteogenin. Proc Natl Acad Sci USA 86: 8793-8797, 1989
15. Buijs JT, Henriquez NV, van Overveld PG, et al: Bone morphogenetic protein 7 in the development and treatment of bone metastases from breast cancer. Cancer Res 67: 8742-8751, 2007.

16. Wang SN, Lapage J and Hirschberg R: Loss of tubular bone morphogenic protein-7 in diabetic nephropathy. J Am Soc Nephrol 12: 2392-2399, 2001.

17. Kamath VG, Chandrashekar A and Rajini PS: Antiradical properties of sorghum (Sorghum bicolor L. Moench) flour extracts. J Cereal Sci 40: 283-288, 2004.

18. Park JH, Darvin P, Lim EJ, et al: Hwanggeumchal sorghum induces cell cycle arrest and suppresses tumor growth and metastasis through Jak2/STAT pathways in breast cancer xenografts. PLoS One 7: e40531, 2012.

19. Park JH, Lee SH, Chung IM and Park Y: Sorghum extract exerts an anti-diabetic effect by improving insulin sensitivity PPAR- $\gamma$ in mice fed a high-fat diet. Nutr Res Pract 6: 322-327, 2012.

20. Audran M: Drug combination strategies for osteoporosis. Joint Bone Spine 73: 374-378, 2006.

21. Turner $\mathrm{CH}$ : Toward a cure for osteoporosis: reversal of excessive bone fragility. Osteoporos Int 2: 12-19, 1991.

22. Joung YH, Lim EJ, Darvin P, et al: MSM enhances GH signaling via the Jak2/STAT5B pathway in osteoblast-like cells and osteoblast differentiation through the activation of STAT5B in MSCs. PLoS One 7: e47477, 2012

23. Chung IM and Kim SH: Analysis methods of phenol compounds. Korean Society of Crop Science 8: 5-12, 2004.

24. Salgado AJ, Coutinho OP and Reis RL: Bone tissue engineering: state of the art and future trends. Macromol Biosci 4: 743-765, 2004.

25. Aaronson DS and Horvath CM: A road map for those who don't know JAK-STAT. Science 296: 1653-1655, 2002.

26. Canalis E, Pash J, Gabbitas B, et al: Growth factors regulate the synthesis of insulin-like growth factor-I in bone cell cultures. Endocrinology 133: 33-38, 1993.

27. Rydziel S, Shaikh S and Canalis E: Platelet-derived growth factor-AA and -BB (PDGF-AA and-BB) enhance the synthesis of PDGF-AA in bone cell cultures. Endocrinology 134: 2541-2546, 1994.

28. Canalis E, Pash J and Varghese S: Skeletal growth factors. Crit Rev Eukaryot Gene Expr 3: 155-166, 1993.

29. Chen D, Zhao M and Mundy GR: Bone morphogenetic proteins. Growth Factors 22: 233-241, 2004.

30. Boon MR, van der Horst G, van der Pluijm G, Tamsma JT, Smit JW and Rensen PC: Bone morphogenetic protein 7: a broad-spectrum growth factor with multiple target therapeutic potency. Cytokine Growth Factor Rev 22: 221-229, 2011.

31. DiGirolamo DJ, Mukherjee A, Fulzele K, et al: Mode of growth hormone action in osteoblasts. J Biol Chem 282: 31666-31674, 2007.

32. Nilsson A, Swolin D, Enerback S and Ohlsson C: Expression of functional growth hormone receptors in cultured human osteoblast-like cells. J Clin Endocrinol Metab 80: 3483-3488, 1995.

33. Kassem M, Mosekilde L and Eriksen EF: Growth hormone stimulates proliferation of normal human bone marrow stromal osteoblast precursor cells in vitro. Growth Regul 4: 131-135, 1994.

34. Huang Y, Kim SO, Yang N, Jiang J and Frank SJ: Physical and functional interaction of growth hormone and insulin-like growth factor-1 signaling elements. Mol Endocrinol 18: 1471-1485, 2004.

35. Joung YH, Lim EJ, Kim MS, et al: Enhancement of hypoxia-induced apoptosis of human breast cancer cells via STAT5B by momilactone B. Int J Oncol 33: 477-484, 2008.

36. Park SH, Joung YH, Park JH, et al: Hypoxia upregulates Hsp90a expression via STAT5B in cancer cells. Int J Oncol 41: 161-168, 2012. 